\title{
Barriers and Drivers to Energy Efficiency - A new Taxonomical Approach
}

B. Sudhakara Reddy

Indira Gandhi Institute of Development Research, Mumbai March 2007 


\title{
Barriers and Drivers to Energy Efficiency - A new Taxonomical Approach ${ }^{1}$
}

\author{
B. Sudhakara Reddy \\ Indira Gandhi Institute of Development Research (IGIDR) \\ General Arun Kumar Vaidya Marg \\ Goregaon (E), Mumbai- 400065, INDIA \\ Email: sreddy@igidr.ac.in
}

\begin{abstract}
This paper develops a new systematic classification and explanation of barriers and drivers to energy efficiency. Using an 'actor oriented approach', the paper tries to identify (i) the drivers and barriers that affect the success or failure of energy efficiency investments and (ii) the institutions that are responsible for the emergence of these barriers and drivers. This taxonomy aims to synthesise ideas from three broad perspectives, viz., micro (project/end user), meso (organization), and macro (state, market, civil society). The paper develops a systematic framework by looking at the issues from the perspective of different actors. This not only aids the understanding of barriers and drivers; it also provides scope for appropriate policy interventions. This focus will help policy-makers evaluate to what extent future interventions may be warranted and how one can judge the success of particular interventions.
\end{abstract}




\title{
Barriers and Drivers to Energy Efficiency - A new Taxonomical Approach
}

\author{
B.Sudhakara Reddy
}

\section{INTRODUCTION}

Energy development is a barometer of economic development. Countries pursuing economic growth are expected to resort to increasing levels of energy use. Achieving these levels of energy production and utilisation through present technologies is not only difficult and expensive, but also environmentally unsustainable. Various studies indicate that increased energy efficiency can bridge the gap between growing demand and reduced energy supply without adversely affecting the quality of service [1-2]. However, as the past experience has shown, this may not happen, unless the issues that hinder the penetration of efficient technologies are addressed [3-5]. There is a gap between the theoretical opportunities for 2

cost-effective energy efficiency investments and the levels that can be achieved practically. The origins of the gap seem to lie in the set of barriers which may be divided into categories such as financial, legal, organizational, or informational. These barriers prevent investments in energy efficient technologies. It is also certain that there are drivers that help increase investments. The barriers hinder the penetration of energy efficient technologies, even though these technologies have been shown to be economically cost-effective. If policies to encourage investments in improved energy efficiency are to be successful, understanding the nature of these barriers and drivers is essential. These policies must succeed in the context of liberalising energy markets, falling energy prices, and increasing the development of a broadbased energy service industry.

\footnotetext{
2 Economic cost-effectiveness depends on both: where the actor-concern boundary is placed (the individual or the society as whole), the time perspective (static or long term dynamics included) and the system regarded (ceteris paribus - all other things equal - all things concerned are changed). Here, the perspective is individual-static-ceteris paribus.
} 
The aim of the present paper is thus to examine the nature of barriers and drivers for energy efficiency. It also analyses the circumstances in which they arise, their relative importance in different contexts, and the manner in which different actors intervene to overcome these barriers. The paper reviews current perspectives on barriers and drivers, classifies them according to their influencing patterns, and provides supporting evidence for their prevalence. Finally, the paper tries to evaluate the effectiveness of different institutions for improving energy efficiency. The debate on barriers and drivers is contentious and is characterised by disagreement over basic theoretical and conceptual principles. Hence, the primary objective of this work is to develop a new systematic theoretical framework.

\section{ENERGY EFFICIENCY - ISSUES}

\subsection{Debate}

There has been a long running debate over the issue of energy efficiency (EE) between energy economists and energy analysts. One issue concerns the rebound effect [6]. Although definitions vary, this effect describes the following linkage: the efficient use of energy leads to an increase in the use of energy. This may partly offset the savings in energy usage achieved by the EE improvement. The rebound effect is rooted in neoclassical economic theory. The extent of the rebound effect depends on the price elasticity of demand. Therefore, the assumption of rational decision making is the precondition for an explanation of this effect.

Saunders [7], argues that 'energy efficiency gains can increase energy consumption by two means: by making energy appear effectively cheaper than other inputs; and by increasing economic growth, which pulls up energy use.' The debate grew more intense in the 1990s, spurred by global warming concerns. The argument for EE, however, is independent of environmental concerns. The market failure that distorts energy use is under pricing of energy 
by regulators and deregulation is preferable to EE into which utilities were forced to reduce energy prices. There are also other market failures, such as split incentives (landlord-tenant), etc [8]. The reality is that while EE is technologically feasible, it will require a significant change in collective approach to making it work. What this means is that, while technologies are already available, the problem lies in their application. Another aspect to which contributions to the EE debate can be associated is what one describes as a matter of 'governmental intervention'. Gunn [9] who investigated the paradigms of EE stated that it is important to recognize that the primary debate is over the optimal level of governmental intervention in energy markets rather than over the optimal level of EE. There are many forms of government intervention such as subsidies and taxes; special purpose loans; facilitation (information systems; well-structured markets; approved suppliers); guarantees for specific risks, or offering insurance; and arranging objective non-partisan product information (e.g., energy labeling)

The justification and degree of governmental intervention is a matter of debate in the international literature $[3,4,10]$. Barriers which are attributed to market failures make governmental intervention necessary and justifiable and a large body of international literature relates barriers to market failures. However, others claim that only few market failures can be defined as such. Haugland, et al [11] argue that most barriers merely reflect 'unaccounted (transaction)' costs or simply result from the consumer's liberty to choose freely his/her convenience and service levels and willingness to accept a higher energy bill for their personal taste or lifestyle. Therefore, governmental intervention might be questionable.

A large body of international literature puts effort in an empirical approach to this question with different objects of investigations and findings [12-14]. Governmental stimulation of the implementation of new technology by promoting associated research and development 
was found to be counterproductive. Although it leads to technological progress it may hinder corporate investments in new technology. Firms may favour to wait for the next generation of technological developments. In the case of a restructuring electricity market prointerventionists ask whether the market alone is able to overcome EE barriers. It is argued that governmental support in promoting EE and load management can be advantageous. Further, an evaluation of US energy labelling programs led [14] concluded that, 'government support is the most critical factor for the success of a labelling program.' Altogether, the challenge of reconciling government and free market contributions with regard to the energy market and EE remains.

\subsection{Characterization of Energy Efficiency potential,}

With regard to EE potential, a distinction has to be made between: (i) the economic potential: achievable by removing market failures; ii) the technological potential: achievable by the additional removal of 'non-market barriers '; ' and (iii) the hypothetical potential: achievable

through the additional elimination of market failures in fuel and electricity markets [15]. This framework is summarised in Figure 1 where various potentials towards EE are represented. The market potential is the efficiency improvement that can be expected to be realized for a projected year under a given set of conditions (e.g., energy prices, consumer preferences and energy policies). The market potential reflects barriers and market imperfections that keep efficiency potential from being fully realized.

The economic potential is the energy saving that would result if during each year of the period in question, all replacements, retrofits and new investments were shifted to the most energyefficient technologies that are still cost-effective at given energy market prices. The

\footnotetext{
${ }_{4}^{3}$ Technical barrier is the one where the new technology might be found wanting or become rapidly outdated.

Market failure is a distinct notion for such problems that can not be solved (in full) by use of market instruments, such as public goods, externalities, etc. Such failures cannot be eliminated though there are some "Paretosanctioned" measures that redeem them. The market failure here means "market imperfections" where market pricing, ownership etc. can be applied successfully (at least in part).
} 
economic potential implies a well-functioning market, with competition between investments in energy supply and demand. It also assumes that the barriers to such competition have been corrected by energy policies. It is assumed that as a result of such policies, all users have easy access to reliable information about the cost-effectiveness and technical performance of existing and emerging options for energy efficiency.

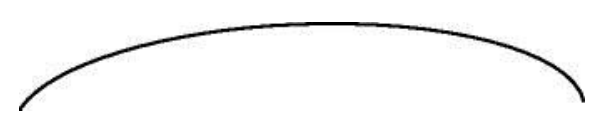

Increasing $\mathrm{EE}$

\begin{tabular}{c|}
\hline $\begin{array}{c}\text { Hypothetical } \\
\text { Potential }\end{array}$ \\
\hline
\end{tabular}

Technical potential

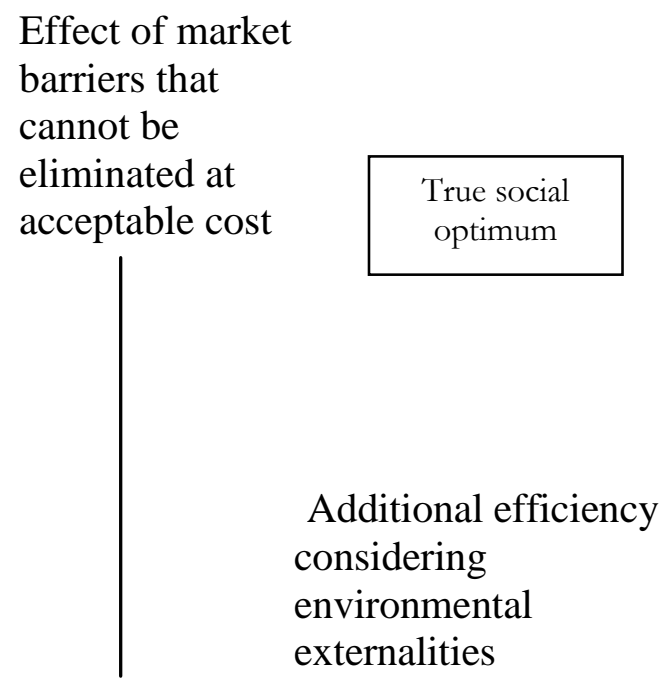

Eliminate high discount rates due to uncertainty Overcome inertia Ignore heterogeneity considering externalities

Eliminate market

failures for EETs

Eliminate those market

failures for resulting in benefit/cost test

Market Potential

Figure 1: Characterization of energy efficiency potential 
The technical potential represents achievable energy savings under theoretical considerations of thermodynamics, where final energy consumption is kept constant, and energy losses can be minimized through process substitution, heat and material re-use, and avoiding heat loss. This can be considered as hypothetical potential and represents achievable energy savings that result from implementing the most energy-efficient technology available at a given time, regardless of cost considerations and reinvestment cycle.

The narrow social optimum in the market for energy efficient technologies represents the rate of energy efficiency uptake that would be observed if all barriers that were deemed to be irrational on a cost-effective basis were eliminated, i.e., if people adopted all measures that could leave them economically better off given the current pricing environment. In this situation, one has to get energy prices right implying that narrow social optimum should include cost effective removal of market failures for energy. The true social optimum would include additional efficiency diffusion that would likely to be seen by considering environmental externalities.

\subsection{Energy Efficiency - Private investor's perspective}

Analysis of $\mathrm{EE}$ and the role of barriers have to be viewed from a private investor perspective.

A barrier will only be overcome if it is low enough to be acceptable and the investor is convinced of this fact. This is especially important for the barrier formed by some risks, as risks are notoriously difficult to judge. In addition, the investor will often, out of selfpreservation, have to take account of the 'worst-case' risk, and that is a far bigger deterrent than the 'probable-risk'. Thus, we can distinguish the barriers to private financing as profitability-related, feasibility-related, information-related, and risk-related.

Profitability-related barriers are those that lessen the financial viability of energy efficiency projects, thereby reducing the willingness of profit-oriented private investors to commit money to such projects. Figure 2 shows the factors and their relationship that enable the 
private investor to accept or reject an energy efficiency project. The representation is in terms of input-output model and the dependent factors.

Figure.2 Representation of profitability barriers

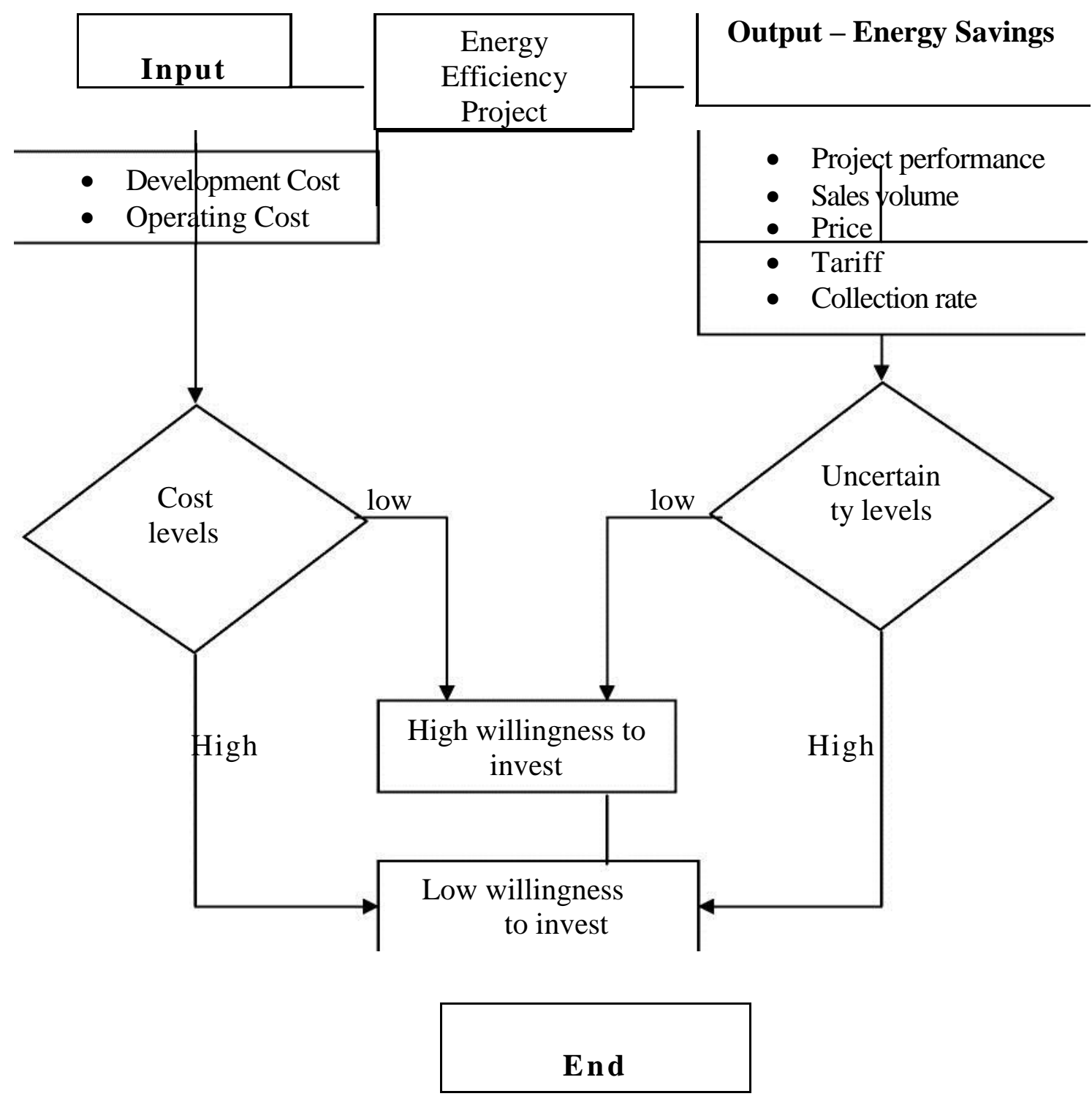


The components making up gross project revenue can include: (a) project performance (e.g., amount of energy saved), (b) sales volume (e.g., number of energy efficient devices sold), (c) price (e.g., price of energy efficient devices), (d) tariff (e.g., electricity tariff), and (e) collection rate (e.g., rate of loan collection on energy efficient equipment sales, rate of utility bill collection). The components of project cost include development and operating cost.

Figure 3: Representation of feasibility barriers

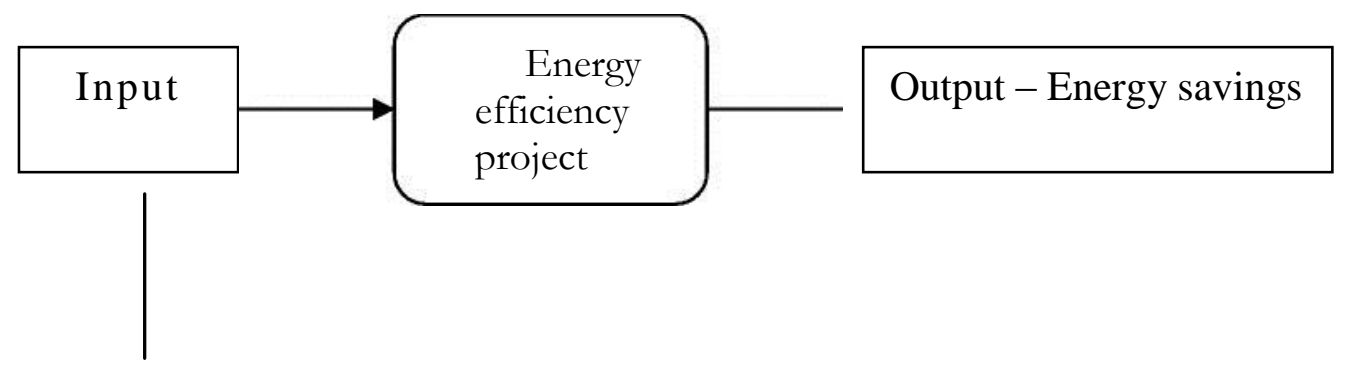

- Information support

- Regulation support

- Technology

- Policy support

Low

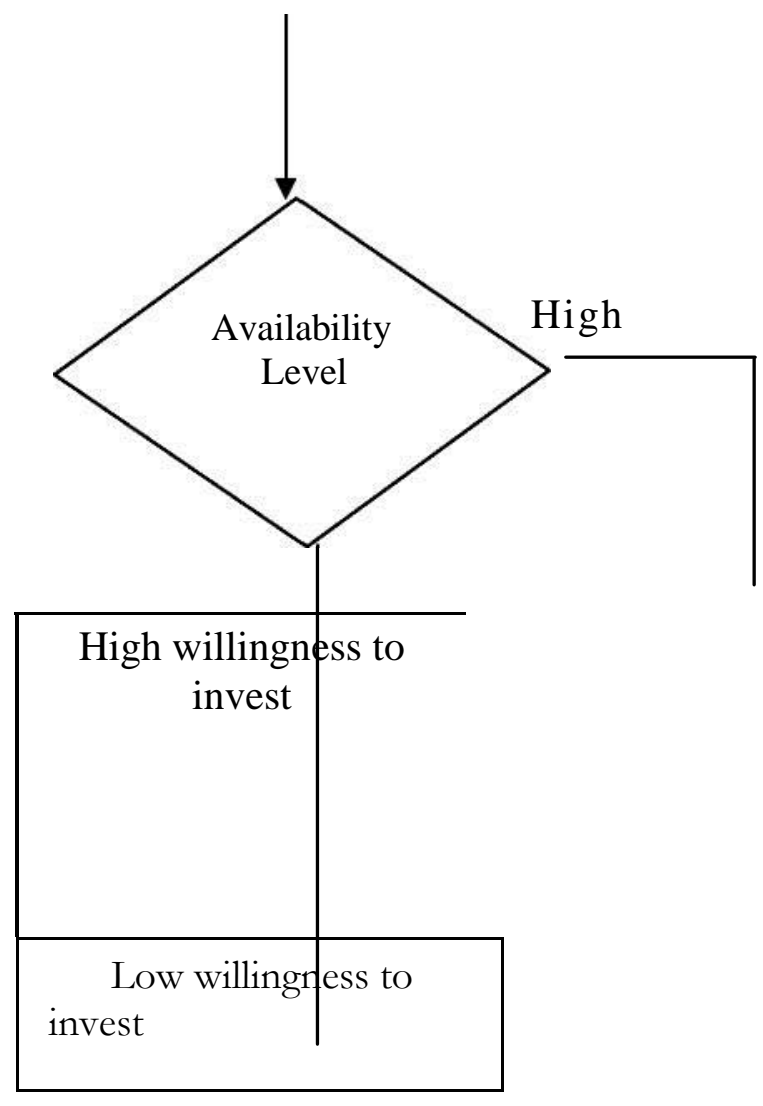


Feasibility barriers (Figure 3) reduce the likelihood of a project being implemented. Unlike profitability barriers, feasibility barriers have no impact on the economics of the project. Rather, they reduce the potential for successful project implementation and therefore increase the uncertainty about the project, ie whether the project can be carried out or not. In some cases, feasibility barriers may be so strong that no amount of profitability can outweigh their negative impact on the investor's decision.

There are some barriers, which affect both profitability and feasibility. For example, lack of information can raise the cost of a project (and thereby lower the profitability) and at the same time put the feasibility of a project in doubt. Investors may be reluctant to commit funds if they cannot verify the data or if they suspect hidden legal obstacles, such as restrictions on foreign ownership, capital repatriation, and so on.

If one wants to study barriers and drivers, the influence they have on the deployment of new energy technologies, and the way in which these barriers and drivers could be modified, one needs a taxonomy. This taxonomy can be linked to each barrier/driver to the exact institutions that create it and the institutions on which it has an influence. Then the taxonomy becomes operational. For example, if someone wants to study the field, in a particular country, for a particular technology, the present taxonomy can be used as a guide to determining what actors should be interviewed, what questions to be asked, and how to bring the replies together for analysis. This approach can be best described as an 'actor' approach. (Ferguson, 2002). In the present study we have defined a new taxonomy that regroups the barriers into micro, meso and macro and then linked the barriers and drivers to institutions. 


\section{BARRIERS AND DRIVERS}

\subsection{Terminology and Main Issues}

Since the paper deals with drivers and barriers to private investment in energy-efficient technologies, the first task is to define the terminology.

A barrier is a pull factor that inhibits investment in energy-efficient technologies. For empirical research on barriers to be fruitful we need to understand the nature of the barriers. This requires clarifying assumptions about the nature of individual behaviour and the relative importance of social structures and the role of markets. We also observe that the consumer's response towards not exploiting the cost-effective technologies is sluggish. We provide explanation for such observations. The identification of the relevant actor is also crucial. For this we have to examine the role of individuals and organizations such as equipment manufacturers and government agencies. The outcome of this process will provide the reasons for the consumer not investing in cost-effective investments.

Drivers can be considered as the factors that promote private investment in energy efficiency, Barriers can be considered as the obstacles to private investment; and Risk can be defined as a special category of barrier with a probability distribution. To be more specific, it can be defined as an uncertainty connected to the future value of the variable, which could be political, legal, financial, and so on. In other words, every factor that facilitates the implementation (feasibility) of a project and/or increases the returns/reduces the risk (profitability) of an investment can be considered as a driver. On the other hand, every factor that does the opposite is a barrier. In the following sections, the main characteristics of 
barriers are discussed. The same arguments are valid with respect to drivers but in the opposite sense.

Firstly, barriers reduce the likelihood of a positive decision by a private investor , that is, they contribute to a no-go decision. There are factors that merely reduce the likelihood of a positive decision, while others single-handedly cause a negative investment decision, which means that some barriers are more influential than others. There are two basic reasons for a no-go decision: insufficient profitability or insufficient feasibility, or a combination of the two. In practice, there are usually several barriers and drivers contributing to either profitability or feasibility issues. The final outcome depends on whether the barriers are overall stronger than the drivers in the investor's mind in terms of driving the decision. This brings us to the second characteristic.

Secondly, barriers can become obstacles only if the investor perceives them as such. If the investor is not aware of a particular factor, or simply determined to proceed to invest, the particular barrier does not influence his decision. This means that the barrier may be real, but it has no influence on the investment decision. In short, reality is only important as far as the investor recognizes it and considers it relevant. There can be perceived barriers that are not real (e.g., the fear of operating in a transition economy, when, in fact, that economy creates no untoward problems for the activity proposed), as well as perceived drivers that are not real (like the expectation of a subsidy that, in fact, will not be given).

Thirdly, some variables can, at the same time act as driving forces and also as barriers. Also, some barriers can be considered as driving forces in some countries and barriers in others.

\footnotetext{
5 The term private investor is here broadly defined as all private profit-oriented sources of capital, including individuals, companies operating in sustainable energy markets, greenhouse gas producers, financial intermediaries, and financial markets. Moreover, it should be noted that we are interested not in barriers and drivers to some vaguely defined concept like 'private participation' but in barriers and drivers to actual additional financial transactions. All forms of private participation that do not involve a financial transfer with the objective to make a profit are not counted. For example, it is not sufficient to succeed in 'communicating' with private actors, to get private investors 'interested' in particular ventures, or to mobilize private sector actors to 'become involved' in public-private partnerships, for example, by attending meetings, making joint declarations, or engaging in consultations on policy.
} 
Therefore a proper barrier-analysis always needs to be a detailed one. This is especially the case if the investor has experience from other countries.

And finally, it is also important to distinguish between the barrier and the result of a barrier. This distinction is important because the resulting impacts of a barrier can help identify/adopt appropriate response measures. Depending on the type of barriers they could result in inadequate financial support, lack of policy support, promote inefficient use of energy, etc. In this paper, we focus mainly on one result: the decision of private actors to provide money or withhold money for energy efficiency.

\subsection{Taxonomies - A Review}

According to neo-classical economic theory one can classify the barriers in terms of market failure and can evaluate short-term policy options to address them. However, this theory neither explains the underlying causes for market failures nor provides directions to increased energy efficiency. The literature contains a great variety of taxonomies, which range from simple lists to useful and logical categorisations of barriers.

A.K. N. Reddy [3] in his path breaking study on the 'Barriers to Improvements in Energy Efficiency' has classified the barriers into: (i) consumer-related, (ii) equipment manufacturerrelated, (iii) utility-related, (iv) financial institution-related, and (v) government-related. Another useful scheme has been developed by Weber [16], which distinguishes between: $(i)$ Institutional barriers: Barriers caused by political institutions, ie state government, local authorities, etc; (ii) Market barriers: Obstacles conditioned by the market; (iii) Organizational barriers: Barriers within organizations, especially within firms; and (iv) Behavioural barriers: Barriers within individuals.

Sorrell [5] prepared a taxonomy by systematically classifying the barriers (based on a comprehensive review of the literature) into three broad categories: (i) neo-classical, (ii) behavioural, and (iii) organizational. In addition, the taxonomy attempts to distinguish 
between barriers that justify policy intervention, those that justify organizational change, and those that do neither.

According to an USAID report [18] the gap in energy efficiency and its use in the market can be explained through: (i) pay back gap, (ii) lack of information, (iii) limited access to capital, (iv) lack of institutional estimates, (v) market structure, (vi) aversion to downtime and innovation, (vii)standardised inventories, and (viii) purchase decision criterion.

Vine et al [19] studied the market barriers in the residential sector and classified them into:(i) lack of information about energy use, (ii) lack of access to information about financing investments in general and energy efficiency technologies in particular, and (iii) low importance given to energy efficiency in decision-making.

According to the Energy and Environmental Economics Programme, San Francisco, California [20], barriers to energy efficiency can be classified as follows: (i) Imperfect information; (ii) Consumer attitudes; (iii) Limited access to capital, and cost disincentives; (iv) Misplaced incentives; (v) Product life cycles; (vi) High consumer discount rates; (vii) Electricity rate distortions and regulatory uncertainty; and (viii) Externalities.

In the paper on Market barriers to energy efficiency: A critical reappraisal of the rationale for public policies to promote energy efficiency', [21] studied the market barriers and concluded that there is a substantial 'efficiency gap' between a consumer's actual investments in energy efficiency and those that appear to be in the consumer's own interest. It was concluded that many of the market barriers can be understood as examples of market failures and do provide a prima facie basis for government intervention.

Reddy BS [10] in his work for the United Nations Environmental Programme (UNEP), has categorized the barriers into (i) financial-economic, (ii) technical, (iii) awareness and information, (iv) institutional-organizational, (v) regulatory, and (vi) personnel and behavioural barriers. 
All these taxonomies are useful for developing measures for empirical studies. In this paper we unify the classifications by defining three broad categories, namely, micro, meso and macro.

\section{MICRO-MESO-MACRO TAXONOMY (M3T)}

\subsection{Barriers to energy efficiency based on M3T}

In order to facilitate the barrier analysis effectively we now define a new taxonomy (named M3T) where the barriers are classified as micro, meso and macro.

\subsubsection{Micro barriers}

Micro barriers are those that occur at the lowest level, for example at the design stage of a programme or a project. These can be referred to as the obstacles that are unique to a particular project. A poorly designed project/programme can make insufficient use of synergies or drivers, or take too little account of barriers. The person to address is the project designer (information, training, support by specialists, etc). Examples include: a medium size or large project, consisting of households from a group of villages or a town, is usually more profitable than dispersed and one-off small projects due to lower transaction costs and economies of scale. A project that consults the representatives of benefited target groups (e.g., consumers, equipment manufacturers, financial institutions) is usually more feasible than the one that is imposed from above.

By changing the features of a project - for example, by modifying incentives for energy savings, replacing the technology, increasing the project size, or creating legitimacy through consultation - the financial viability and feasibility could be improved. Also, changes in project design can reduce the internal barriers to profitability and feasibility.

\subsubsection{Meso barriers}

Meso barriers occur at the intermediate level, i.e., in the implementation stage. These relate to the organizations affiliated with the project. These barriers can be common to a wide variety 
of projects and can be tackled with efficient organizational design, human resource, as well as time management. Examples include: (i) The implementing agency may be understaffed, bureaucratic, or lack proper incentives for promoting energy efficient lighting systems; (ii) The project target groups (e.g., rural households) may be small, inexperienced and under capitalised; (iii) The consumers may lack experience in a particular lighting technology (iv) The implementation authority may be unaware about the details of a geographic area where the project has to be implemented; and (v) The government authorities may put forth rules and procedures that can raise the cost of the project and/or reduce the feasibility of implementation.

\subsubsection{Macro barriers}

The macro barriers occur at the highest level: state, market, and civil society. Since these barriers are not project or organization-specific, they cannot be altered by changing project or organizational design. For project sponsors and financiers, macro barriers are externally driven and are difficult to influence (unless they have the power of influencing policies, market, or culture). In some cases, projects include policy components, which can affect macro variables (e.g., electricity tariffs, laws about who will keep financial savings from energy efficiency projects, subsidies, etc.). It is usually easier for project sponsors and investors to change the project characteristics than it is to influence government policies such as electricity tariffs and subsidies. Therefore, many projects do not even attempt to change macro variables and instead focus on overcoming or neutralizing the adverse effects of macro barriers through increased financial subsidies - or, more rarely, through innovative project and organizational design. The benefits of tackling macro barriers are usually much greater than focusing merely on micro and meso level barriers, and the sustainability of results over time is much greater as well. 


\subsection{D representation}

Targeting of barriers is illustrated in Figure 4 in three dimensional (3D) space. The three axes represent sustainability ( $\mathrm{X}$ axis), difficulty ( $\mathrm{Y}$ axis) and benefits ( $\mathrm{Z}$ axis). Points on $\mathrm{XY}$ plane measure targeting macro barriers, YZ plane targeting meso barriers and ZX plane targeting micro barriers. The point $\mathrm{P}$ in the box (3D space) represented by a line from origin shows the composition of various types of barriers for a given target efficiency potential. The components (micro, meso and micro) can be determined by projecting this line onto respective planes. Projection on $\mathrm{X}, \mathrm{Y}$ and $\mathrm{Z}$ axis gives the role of individual factors (sustainability, difficulty, and benefits). This representation can be used to analyse various factors targeting the barriers. The representation can be used for synthesis also when externalities are given. According to the figure, if we target micro barriers (marked ' $\mathrm{XZ}$ ' in the figure), we can expect relatively low benefits and sustainability of results, but these measures are also relatively easy to implement. But if we want to influence macro barriers (marked ' $\mathrm{XY}$ ' in the figure), we can expect much greater difficulty, but also much higher benefits that are sustainable over time. Meso barriers lie somewhere in between on all dimensions (marked 'YZ' in the figure).

Figure 4: Targeting micro, mesco and macro barriers

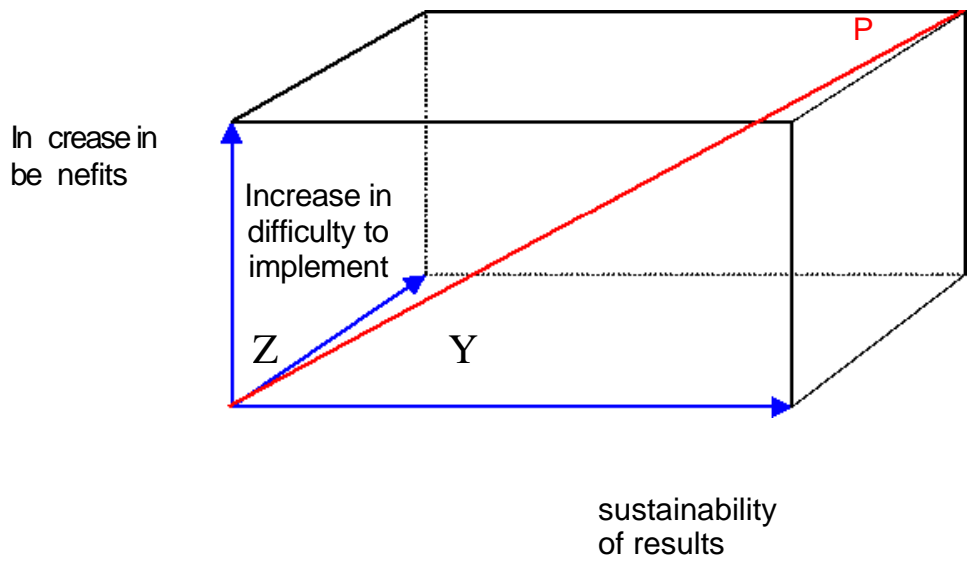


Barriers relating to the state are those that can be traced to the behaviour (action or inaction) of governments or state-run organizations (e.g., public utilities). Barriers relating to the market are those that can be traced to the behaviour of individuals, private firms and financial institutions, which reflect the prevailing market structure. And finally, barriers relating to civil society can be traced to the behaviour of NGOs, academic institutions and other civil society organizations (CSOs). While the distinction between state, market and civil society barriers is useful as a means of classification, in practice, there are linkages between them. For example, markets react to policy changes and vice versa; policy is affected by the lobbying of firms; and NGOs and other civil society organizations operate within a political and economic context. Efforts to remove or reduce macro barriers need to pay attention to these relationships in order to be effective.

The barriers can be further classified into internal (barriers due to flaws in the project or the organization) and external (policy, market, and civil society barriers). Internal barriers are easier to overcome, because they require only changes in the project or the organizations involved in the project whereas external barriers require policy changes, measures to affect the workings of markets, or measures to influence civil society or the culture of a country. In designing a complete model, there are numerous variables that could potentially be relevant: there are variables in the three categories of project, organization, and policy design, and there are variables in the causal pathway (the categories of drivers and barriers).

In summary, an analytic taxonomy starts with the basic reasons for lack of private investment: the perception of lack of profitability and/or lack of feasibility (it does not matter what the real barriers and drivers are; their effect depends only on the perception of the investor). This leads to a distinction between factors that cause the lack of profitability and others that cause the lack of feasibility. These factors may occur at three levels, micro 
(project), meso (organization), and macro (policy, market, civil society). At each of the three levels, there are measures that can address the profitability and feasibility issues..

\section{CAUSAL MODEL OF PRIVATE INVESTMENT DECISION}

If the objective is to maximize private investment in energy efficient technologies at a minimum cost to the consumer, we need to find out which factors (drivers and barriers) influence private investment decisions. But a list of factors is not sufficient. We need to know the relative contribution (causal weight) of these factors in terms of influencing investment decisions. Only then we are able to design and prioritize measures to mobilize private capital for clean technologies. There are two types of measures: (a) those that stimulate the drivers of private investment, and (b) those that reduce, remove, or overcome the barriers to private investment. The best measures are those that have the greatest positive effect on mobilizing private capital relative to their cost for the taxpayers. In other words, we need to find the cheapest way to stimulate the key drivers and to remove the key barriers. For this, it is necessary to develop a causal model, which shows how the policy (macro), organizational (meso), and project (micro) level stimuli mechanisms interact with the determinants of private investment (barriers and drivers) to create an investment response. This leaves us with the task investigating the relative importance of barrier and driver variables in stimulating or preventing private investment. Then we would be able to investigate the cost-effectiveness of various measures in stimulating the drivers and removing the barriers (i.e., the costeffectiveness to mobilize private capital).

Cost-effectiveness is defined in terms of 'value' for money. In our analysis, achieving costeffectiveness means maximizing the present value of private investment flows in relation to public capital spent to stimulate those flows. It may be worth reflecting upon why private investment is chosen as the dependent variable rather than a more traditional public policy target such as social optimum, income distribution, or environmental benefits. At first sight it 
might appear natural to choose environmental benefits as the dependent variable. For example, the GEF defines cost-effectiveness in terms of maximizing the global

environmental benefits relative to cost. In the area of climate change, the GEF measures how much greenhouse gases were abated relative to the capital spent. Cost-effective projects are those that mitigate a specified amount of greenhouse gas emissions for a given cost.

If the policy objective is to maximize environmental benefits, then the target should not be maximizing environmental benefits but rather private investment - specifically, maximizing private investment in clean technologies at a minimum cost to taxpayers. If one wants to maximize environmental benefits, why is it necessary to maximize private investment. This paradox is explained as follows: first, the sum of private investments in clean technologies is presumed to be positively correlated with environmental benefits (the higher private investment, the greater environmental benefits). Second, the more private investment, the faster will be the process of commercialization of clean technologies. This in turn will maximize environmental benefits over time, because if environmental technologies become commercial, the amount of private financing will likely dwarf the current environmental investments that are mostly publicly funded. Shifting environmental investments to the private sector will reduce the dependence on taxpayer support and on scarce public budgets, and open environmental markets to the considerable sums of money looking for investment opportunities in national and global financial markets.

\subsection{Stricture of the causal model}

The structure of the causal model is illustrated in Figure 5. The causal model links the stimulation mechanisms (the independent variables) with the private investment response (the

\footnotetext{
${ }^{6}$ Cost-effectiveness is one of ten operational principles for development and implementation of the GEF's work programme, 'The GEF will ensure the cost-effectiveness of its activities to maximize global environmental benefits.' (GEF, 1966b)

7 The assumption is not that investment in clean technologies is the only way to mitigate environmental problems. Rather the assumption is that without a significant shift of investment from polluting technologies to clean technologies, the world's environmental problems cannot be solved.
} 
dependent variable) through the determinants of private investment (linking variables in the causal pathway). The input variables (stimuli mechanism) are categorized into macro, meso and micro. The variables are ordered from those that stimulate the drivers to those that overcome the barriers. The linking variables themselves are ordered from drivers to barriers. The effect of linking variables range from promotion of investment to prevention. The model is general and may include non-linear relationships.

\section{Causal Pathway}

Transmission mechanism linking independent and dependent variable

\section{Independent \\ Variables $\left(\mathbf{X}_{\mathrm{a}}-\mathbf{X}_{\mathbf{n}}\right)$}

Stimuli Mechanisms

The mechanisms to mobilize private capital

\section{Linking \\ Variables $\left(\mathbf{r}_{\mathbf{a}}-\mathbf{r}_{\mathbf{n}}\right)$}

Determinants of Private Investment

Factors that influence the decision of private investors

\section{Dependent \\ Variables (y)}

Investment

Response

The mobilization outcome

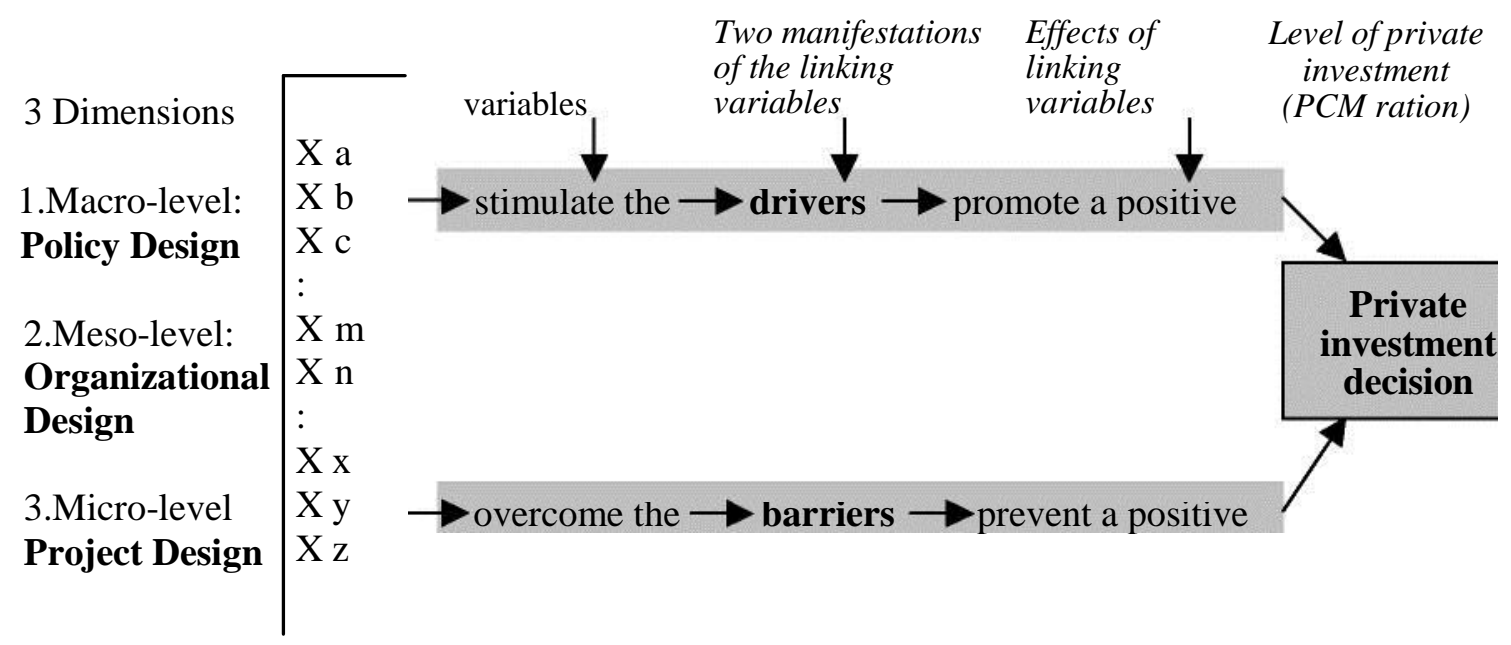

Figure 5. Structure of causal model 


\subsection{Factors}

Unpredictability: Private investors are not a homogenous group; they have different goals, different perceptions, different decision-making procedures, and they apply different criteria for investment. If two investors face identical scenarios (the same barriers and drivers), there is no guarantee that they will make the same decision.

Multiple levels and linkages: Private Capital Mobilisation (PCM) mechanisms can be applied at three levels: the policy level, the organization level, and the project level; and the interaction between multiple mechanisms at different levels can make it difficult to trace the linkages and identify the significance of each contributing cause.

Implementation: The level of PCM may depend not only on the properties of the instruments (type, characteristics, scale, etc.), but also on the manner of implementation.

Context: The level of PCM may also depend on the context/environment within which the variables (instruments, barriers, drivers) are embedded. For example, a specific instrument may not be effective in mobilizing private capital unless there is a coherent overall policy design, organizational design, or project design.

Endogeneity: There is a possibility that there is a recursive effect between private investment and the stimuli that are applied (endogeneity). The causal model suggests that investment increases when stimuli increase, but it is equally plausible that stimuli increase when investment increases. For example, dialogue between policy-makers and investors may create endogenous effects.

Nonlinearity: A 'multivariate regression' is based on the assumption of (at least approximate) linearity: when a variable $\mathrm{Y}$ (say, propensity to invest/investment response) depends on variables $\mathrm{x} 1 \ldots \mathrm{x}_{\mathrm{n}}$, the assumption is that the relation is approximately linear in all of the variables. For investment decisions, this is not necessarily the case. Normally, there 
will be a large number of conditions, which all have to be satisfied before an investment decision can be made. Any one condition, when not fulfilled, can block the decision to invest, independently of the values of all other variables. No linear approximation can cover that. 8

\subsection{Variables}

The causal model is made up of the dependent variable, the independent variables, and the causal pathway that links the two:

(1) The dependent variable is the investment response, that is, the decision of private investors, which can be either 'yes', 'no', 'partially', 'maybe in the future', or 'yes, subject to condition'. In other words, the decision is to finance, to refrain from financing, to finance it partially, to postpone a final decision, or to make the investment decision contingent on the fulfillment of certain additional conditions such as changes in the design of policies, organizations, and projects. The level of private investment is ideally measured in terms of a cost-effectiveness ratio such as the Private Capital Mobilization ratio (PCM ratio). The PCM ratio is an indicator that shows how cost-effectively measures (applied on different levels policies, organizations, and projects) have influenced the drivers and barriers to private investment, thus stimulating additional private investment. The ratio is calculated by the present value (PV) of private capital mobilized, divided by the PV of public expenditure on measures applied to mobilize private capital.

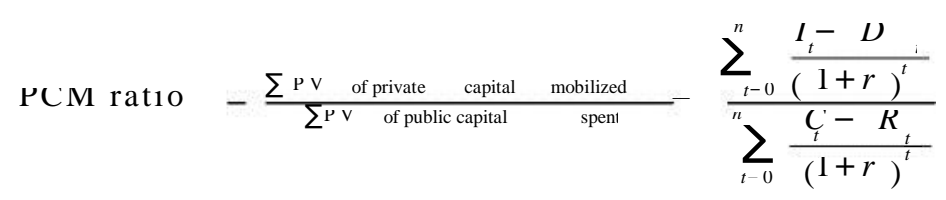

Where

$\mathrm{I}_{\mathrm{t}}=$ amount of private capital in time $\mathrm{t}$

$\mathrm{D}_{\mathrm{t}}=$ amount of private capital divested in period $\mathrm{t}$

${ }_{8}$ One might say that it could be possible to design some other form of non-linear model, but then the number of degrees of freedom in choosing the model's structure is infinite. No method exists to select the 'right' model structure. A linear model will not work, and there is no way to select a non-linear one. 
$\mathrm{C}_{\mathrm{t}}=$ amount of public expenditure in time $\mathrm{t}$

$\mathrm{R}_{\mathrm{t}}=$ amount of public expenditure divested in time $\mathrm{t}$,

$\mathrm{r}=$ project finance rate (ie the rate of return appropriate for the overall level of risk)

(2) The independent variables are the stimuli (synonymous with terms like measures/actions/mechanisms/instruments) applied by the government or multilateral institutions to influence private investment decisions, or for other reasons that could affect the mobilization outcome. The stimuli mechanisms can either be carrots (eg grants) or sticks (eg threats to introduce efficiency regulation unless voluntary action is taken).

(3) The causal pathway is the transmission mechanism linking the stimuli (the independent variable) with the investment response (the dependent variable). This transmission mechanism consists of the variables that private investors consider before making an investment decision. These variables could be called 'the determinants of private investment' or 'investment criteria'. They can have two manifestations either as drivers of private investment, or as barriers. Whether these variables actually act as drivers or barriers depends on the perception of the investor.

\subsection{Outcome}

In the present analysis, achieving cost-effectiveness (in terms of 'value' for money) means maximizing the present value of private investment flows in relation to the public capital spent to stimulate those flows. It may be worth reflecting upon why private investment is chosen as the dependent variable (or the primary objective) rather than the more traditional public policy targets such as social optimum, income distribution, or environmental benefits. At first sight it might appear natural to choose environmental benefits as the dependent variable. For example, the GEF defines cost-effectiveness in terms of maximizing the global 
environmental benefits relative to cost. In the area of climate change, the GEF measures how much greenhouse gases were abated relative to capital spent. For GEF, cost-effective projects are those that mitigate a specified amount of greenhouse gas emissions for a given cost. These can be identified as projects with low unit abatement cost (UAC), for example, the cost per unit of greenhouse gas emissions abated or sequestered (expressed as US dollars

per ton of carbon equivalent $(\$ / \mathrm{tC}))^{\prime}[22] .10$

If the policy objective is to maximize environmental benefits, then the target should rather be with a specific aim to maximize private investment in clean technologies at a minimum cost to taxpayers. If one wants to maximize environmental benefits, why is it necessary to maximize private investment? This paradox is explained as follows: firstly, the sum of private investments in clean technologies is presumed to be positively correlated with environmental benefits (the higher the private investment, the greater the environmental benefits). Secondly, the more the private investment, the faster will be the process of commercialization of clean technologies. This in turn will maximize environmental benefits over time because if environmental technologies become commercial, the amount of private financing could dwarf the current environmental investments that are mostly publicly funded. Shifting environmental investments to the private sector will reduce the dependence on taxpayer support and on scarce public budgets, and open environmental markets to the considerable sums of money looking for investment opportunities in national and global financial markets.

\footnotetext{
9 Cost-effectiveness is one of ten operational principles for development and implementation of the GEF's work programme, 'The GEF will ensure the cost-effectiveness of its activities to maximize global environmental benefits.' (GEF 1996).

${ }_{10}$ Cost-effectiveness is not always the decisive criterion for project selection.

11 The assumption is not that investment in clean technologies is the only way to mitigate environmental problems. Rather the assumption is that without a significant shift of investment from polluting technologies to clean technologies, the world's environmental problems cannot be solved.
} 


\subsection{Casual Linkages}

A systematic analysis is still valuable and necessary, even if it is not possible to aim for general cost-effective rankings among different mechanisms, as well as rankings between the most important to the least important barriers and drivers. The value of this analysis lies particularly in making explicit how private capital mobilization works as a causal process something that is not necessarily clear, neither to the outside observer, nor to the investor. The most important gap in the literature is not the knowledge of policy, institution and project designs, nor the knowledge of barriers and drivers, but the systematic understanding of the causal processes and the tracing of causal relationships in this subject area. Figure 6 illustrates causal relationships in comparison with Figure 5.

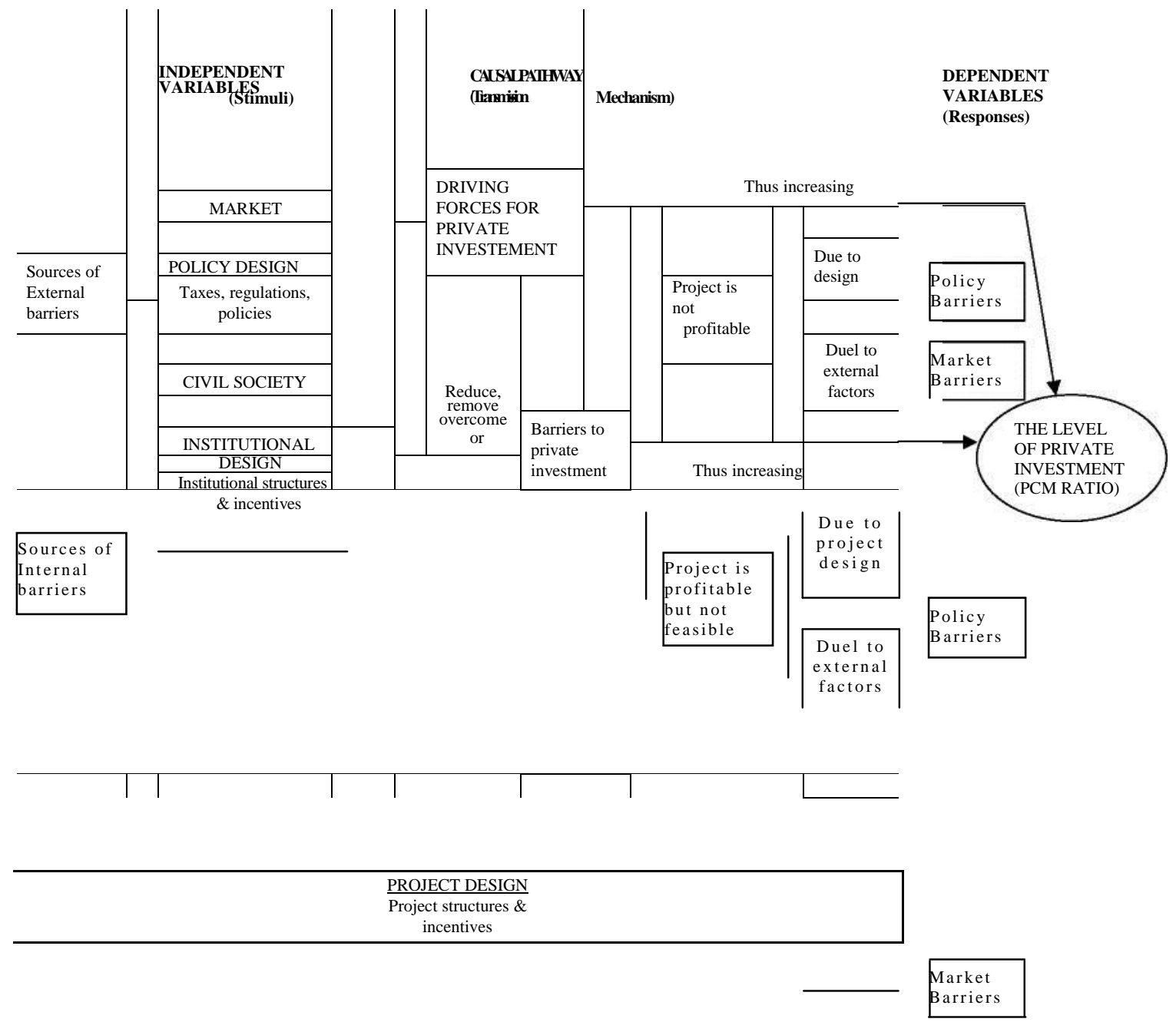

Figure 6. Causal linkages 
The figure depicts the causal pathway - starting from stimulation to initiate or support projects - Causal factors (barriers/drivers) - Investor response (project is financed or not). The causal model shows the structure and logic of the model (transmission mechanism). It 
indicates that the challenge for any stimuli mechanism is to stimulate the drivers and/or to reduce, remove, or overcome the barriers to private investment. The figure also shows that the drivers and barriers can have an effect both on the profitability as well as on the feasibility of the project: the more barriers exist, and the stronger their cumulative effect, the less profitable the project will be, and the more likely that it cannot be implemented. Such links with feedback mechanism would help in the identification of corrective measures at every step.

As illustrated in Figure 6 the barriers can be further classified into internal (barriers due to flaws in the project or the organization) and external (policy, market, and civil society barriers). Internal barriers are easier to overcome, because they require only changes in the project or the organizations involved in the project whereas external barriers require policy changes, measures to affect the workings of markets, or measures to influence civil society or the culture of a country. In designing a complete model, there are numerous variables that could potentially be relevant: there are variables in the three categories of project, organization, and policy design, and there are variables in the causal pathway (the categories of drivers and barriers).

\subsection{Example variables}

To make this abstract model more accessible, Table 1 provides a list of examples of variables mentioned in the casual model classified as barriers or drivers based on their properties (e.g., high or low). It can be noted that the variables relate to returns, risk or feasibility, or a combination of these. However, this list is not comprehensive. 
Table 1. Variables in the causal model (examples)

\begin{tabular}{l}
\hline INDEPENDENT VARIABLES x1 \\
$\ldots \mathrm{x}_{\mathrm{n}}$ \\
\hline POLICY DESIGN \\
affects drivers and barriers 4 \\
Legal, tax and regulatory changes \\
- Electricity tariff reform \\
- Reduction of subsidies to fossil \\
fuels \\
- Green tax reform \\
- Legislation enabling independent \\
power producers \\
- Removing current $\mathrm{R} \&$ D bias in \\
favour of fossil fuels and nuclear \\
energy $\quad$ Policies and programmes \\
$\quad$ aimed at speeding up the \\
$\quad$ process of investment \\
$\quad$ System-wide information \\
$\quad$ dissemination \\
agreements \\
- International environmental \\
Protocol \& Flexible Mechanisms \\
Development Mechanism \\
GHG emission permits
\end{tabular}

\section{CAUSAL PATHWAY R}

DRIVERS AND BARRIERS

to private investment 4

- Costs relative to project size; e.g.,

- Transaction costs (e.g., initial start-up costs, due diligence)

- Capital costs relative to market discount rates

— Operating costs

- Financing costs

- Electricity tariffs

- Trade policy (e.g., import duties and subsidies)

- Subsidies and taxes on fossil fuels \& EE (also indirect subsidies such as on transport of coal)

- Specifications in ownership construction and financing model to assure sufficient

return over the life of the project

- Technology performance

— Simplicity \& serviceability

—Efficiency (including T \& D losses)

- Reliability

- Design and construction risk (e.g., time

and cost-to-completion)

- Market risk (e.g., sales risk and uncertain future demand of electricity)

- Residual value risk

- Technology/obsolescence risk (e.g., uncertainties relating to forecasting technological innovations)

- Policy risk

- Fossil fuel price risk

- Contract enforcement risk

- International climate change negotiations, and likelihood of forceful government action.

- Foreign currency fluctuations (currency risk) and extent of local manufacturing

- State of infrastructure in a country: (a) general infrastructure such as roads, telecommunications, and (b) technology specific infrastructure such as availability of local manufacturers, service institutions.

- Procurement policies, e.g., legal requirements to do competitive bidding based exclusively on lowest cost among all power sources vs. EE

- Availability of data

- Management capacity

- Perception of EE technologies

- Knowledge by potential customers

- Marketing \& sales infrastructure

- Local maintenance \& support services

- Bill collection (including ability to speed up late payments and pursue payment default)

- Coordination of national $\&$ international efforts

- Integration of project with

utility planning processes

- Energy planning methodologies (e.g., do they reflect the small-scale, modular nature of EE)

- Political 29 support for the project

PRIVATE INVESTMENT

...thus increasing the PCM ratio

There are types of Private Capital

Mobilization

- Direct PCM for particular

projects

- Indirect PCM through

multiplier effects

The level of private investment, ideally measured in terms of a cost-effectiveness ratio such as the Private Capital Mobilization ratio (PCM ratio)

PCM ratio =

$$
\sum_{\text {PV of public capital sp }}^{\text {PV of private capital mob }} \sum
$$

at two 
levels: (a) the policy-making level and (b) energy planners, utility managers, and other implementing agents

- Macroeconomic stability

- Income levels of target population

- Access to credit \& leasing

- Investment policy regimes

- R \& D policy

- Private power legislation

Other factors that may influence investment decisions:

- Whether investor has time and attention span

- Mood of the investor in moment of decision-making

- 'Irrational' factors (e.g., whether the investor likes the members of the project team)

- 'Gut' feelings

ORGANIZATIONAL DESIGN

affects drivers and barriers 4

Institutional programmes

- EE projects implemented by IFC

- UN ECE energy efficiency projects

\& technical assistance

Procedures and incentives

- Bonus for developing EE projects

- Incentives for hiring experts on EE

- Incentives for collaborating with

other departments and institutions

PROJECT DESIGN

affects drivers and barriers 4

Financial incentives

- Grants

- Concessional loans

- Guarantees

- Equity investments

Design mechanisms

- Clarity of project objectives

- Contracts

- Planning and risk appraisal

- Quality project participants

- Technology choice

- Sound marketing and after-sales

service

\section{STAKEHOLDER ROLE}

There is a growing recognition that the usual investment decisions such as payback period, rate of return on investment, net present value, etc, do not account adequately for actual consumer behaviour. Technical solutions are not likely to succeed unless there is an interface between various actors in the field of EE. In conventional energy programmes, there are only two main participants, that is, the suppliers and the consumers. In the EE system, there are 
many actors such as the consumer/investors, utilities, government agencies (ministries, state agencies, parliamentary commissions, and intergovernmental commissions), financial institutions, regulatory bodies, local authorities, research and development organisations, equipment manufacturers, market institutions, energy consultants, NGOs, energy service companies, the International organizations (e.g., Intergovernmental Panel on Climate Change), etc. who play important roles. If the EE programmes are to be widely accepted, all these parties should work together. Each actor has relations to other actors. The actor experiences constraints and stimuli; has abilities and weaknesses; and holds rights, responsibilities and obligations. All these lead to series of decisions. All the actors, and their decisions, describe the whole socio-technical structure and the processes that occur.

While discussing the drivers and barriers, it is important to consider the role of actors such as the national government, regional and local authorities, supranational bodies such as international development agencies, the United Nations and its specialised bodies, the World Bank Group, international and national professional and trade bodies, etc. One could try to indicate which 'actor' has the power to create/reduce/remove certain barriers and on which actors the particular barrier has an influence. One could also try to indicate whether the barrier can be modified in the short term (e.g., through a subsidy), in the medium term (e.g., through new legislation), or only in the long term (e.g., through improving general education), or probably never (e.g., in the case of cultural/religious barriers). One could also look at the mechanisms as means to overcome the usual constraints and pave the way for smooth functioning of programmes. This, in turn, encourages the removal of barriers and positively affects investments. Such an 'actor-oriented' approach would give clearer insights into barrier analysis. Through such an approach we can find out the role of actors. For example, if any barrier is named, we can see who created it, and who, therefore, is (in 
principle) able to remove it. Figure 7 illustrates actors in the field of EE in general, from 'macro', meso, and 'micro' perspectives

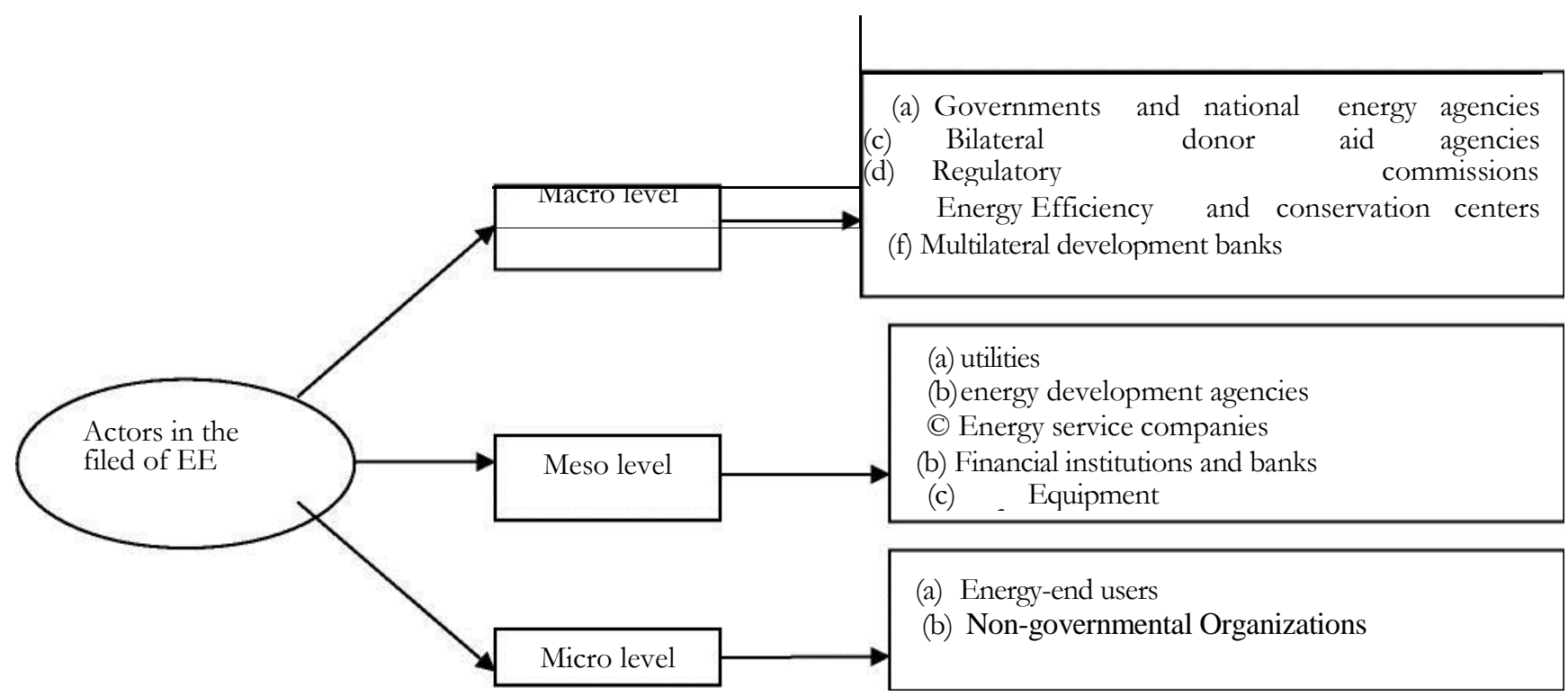

\section{Figure 7: Actors' Perspectives}

At the micro level: To design better programmes, they are the persons/consumers to address (information, training, support by specialists, etc).

At the meso level: Organisations such as utilities, energy development agencies, service companies, etc. Through new incentives, organizational reform, and other changes, barriers can be reduced or removed.

At the macro level: Relate to the 'higher-level' institutions (state/market/civil society) that determine the setting under which the lower levels have to operate.

The actions needed to address barriers are different for each. Through this approach, we not only need to look at the barriers themselves, but also at the institutions/situations that create the barriers. Each actor would then have two roles: (i) to carry out a project at his own level, the actor has to work within existing 'external constraints' given by 'higher-level' institutions, and (ii) establish conditions (either barriers or drivers) for other actors at a 'lower 
level'. This approach can be used in surveys, by asking every actor to describe the types of barriers affecting profitability and feasibility as he perceives them.

Each actor in the field of EE has a specific function, but even without being an active performer, everybody can be positively influenced by EE thanks to its character of positive externality. Everybody has a responsibility: governments, industries, business associations, donors, and international institutions; they all should recognize their respective roles. The EE process can be completed only by cooperation, by a common achievement. If the government wants to promote EE, it needs to see how the whole system can be modified which can lead to more EE-directed decisions. Table 2 demonstrates main functions of the actors in the field of EE. Each of them has a specific role(s) in the process of the implementation of EE. They are mutually connected:

\section{BARRIER TREATMENT}

It is important to explore the relationship between the independent variables (the stimuli mechanisms) and the linking variables (the drivers and barriers). This relationship can be described as a process of stimulating the drivers and overcoming the barriers to private investment. Overcoming the barriers would reduce the overall financing need for energy efficiency and promote sustainable development. It is important to recognize that the process of 'overcoming' barriers is not a single process, but, in fact, three separate processes. 
Table 2: $\quad$ Functions of the stakeholders in energy efficiency systems

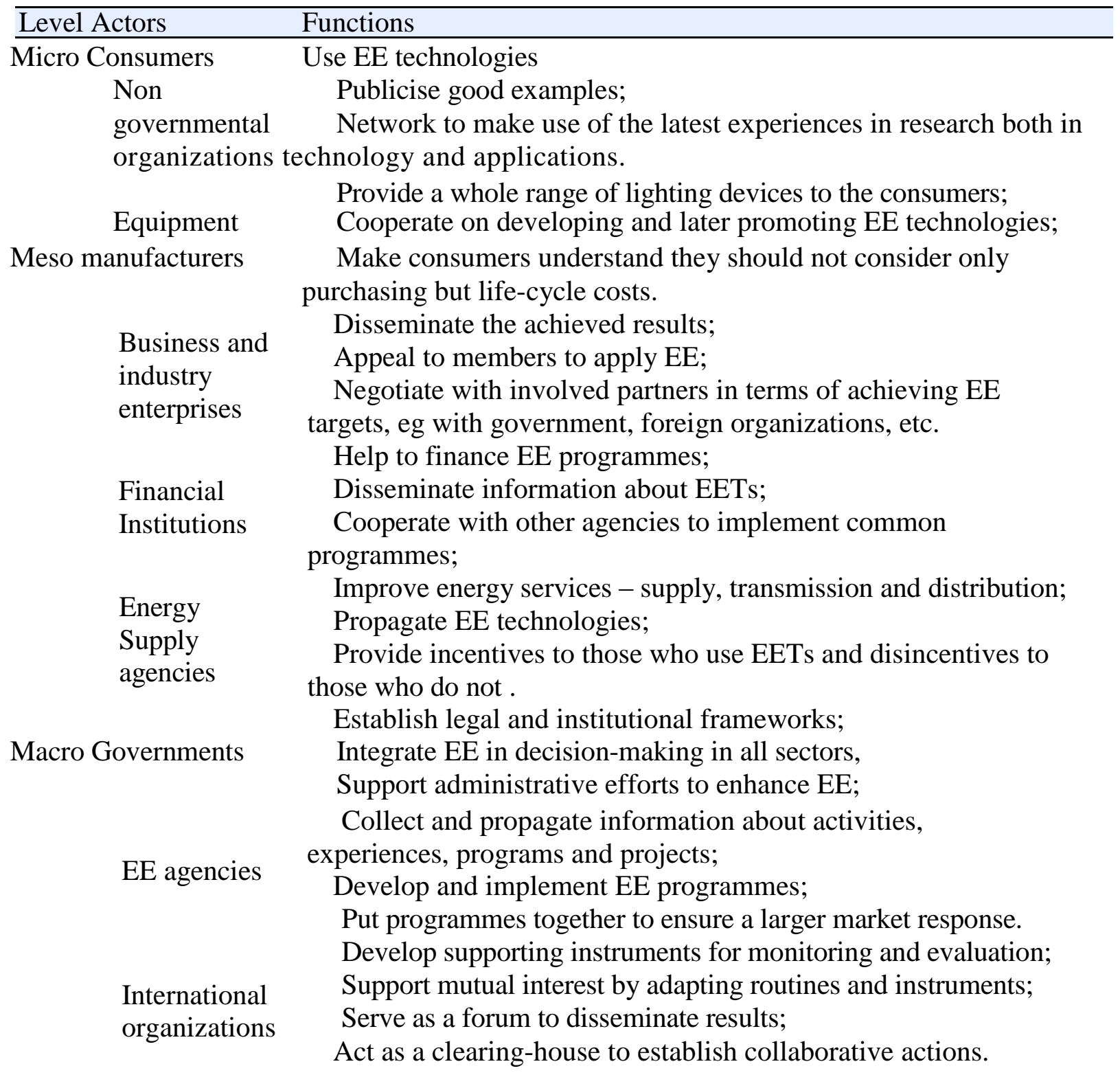

Source: based on OECD, 1999

Type 1: Removing a barrier (or risk) means getting rid of a barrier altogether, so that all present and future projects no longer face that barrier. For example, if a government repeals a law that obstructs energy efficiency, the change of legislation will affect all present and future projects. Unless the law is reintroduced later, the barrier is removed altogether. In terms of policy objectives, this is the most desirable form of overcoming barriers. 
Type 2: Reducing a barrier (or risk) means that the barrier remains in place, but that its deterrent effect is diminished. For example, if a government increases electricity tariffs but not sufficiently to cover long-run marginal costs, the barrier of distorted electricity pricing is reduced but not removed.

Type 3: Avoiding a barrier (or risk) means that the barrier can be overcome or avoided during a particular programme, while remaining in place for others.

While Type 1 and Type 2 are actions addressed primarily to the actor who has created the barrier, Type 3, is addressed primarily to the actor who wants to 'work around' the barrier (a different person/institution).

Of all the approaches to overcome barriers, removing obstacles (Type 1) may be the most expensive and difficult. Yet, it is probably the most cost-effective, because in this way, barriers disappear for all projects in an economy - present as well as future. In practice, however, the most common approach seems to be the least effective, namely, the avoiding of barriers (Type 3). It seems that many agencies promoting energy efficiency merely 'lift' projects over the same hurdles time and again. From a public policy perspective, this is not a desirable approach, as it represents a waste of public funds.

A case in point is the Global Environment Facility (GEF). The Operational Strategy of GEF states that the removal of barriers to energy efficiency and renewable energy are central to the mission of the organization (GEF 1996). The GEF supports projects (and 'programmes') that tackle institutional and structural shortcomings, and in this way modify the barriers and drivers. Two of the ten operational programmes at GEF are specifically aimed at removing barriers to energy efficiency (Operational Programme $\# 5^{12}$ ) and renewable energy

\footnotetext{
The United Nations Framework Convention on Climate Change (UNFCCC) seeks to stabilize atmospheric greenhouse gas concentrations at levels that would prevent dangerous anthropogenic interference with global climate. The Operational Strategy of the GEF puts initial emphasis, among others, on the removal of barriers to energy conservation and energy efficiency.
} 
(Operational Programme \#6) [22]. However, the incremental cost principle, based on which GEF distributes its funds, contradicts this objective because it usually results merely in 'lifting' the projects over barriers, rather than reducing or removing the barriers that create the incremental cost problem in the first place. As a result, the barriers remain in place, 'waiting' to obstruct the next project.

To illustrate this important point, consider an energy efficiency lighting programme, which addresses two main barriers: high initial cost of efficient light bulbs and lack of consumer awareness. Given enough financial resources and successful project implementation, both barriers can be overcome. This, however, does not guarantee that those barriers will permanently disappear. It may happen that the consumers, who got used to highly subsidized prices, make it difficult for the manufacturer to sell the bulbs at commercial prices once the project is over. This is because the consumers tend to forget the benefits of efficient light bulbs after a while, or because they are simply unwilling to accept increased prices. In order to prevent this, incentives must be given to the project developers to ensure the durability of the barrier removal measures so that the impact stretches beyond the individual programme. The sustainability of barrier removal should be one of the main criteria by which development agencies allocate funding to programmes. This should be made mandatory in all the business plans submitted as part of applications for energy efficiency funding.

While barrier removal (Type 1) is quite rare, many projects achieve barrier reduction (Type 2). It can be hypothesized that all successful energy efficiency projects contribute to the reduction of costs or other barriers, thus accelerating the process of commercialisation. Types 1 and 2 refer to possible actions by an authority, which is responsible for the barrier/driver, or has the power to modify it. The primary target for barrier removal and reduction should be the government, but other institutions may also be able to influence the process in direct and 
indirect ways. For example, rather than lobbying a reluctant government, it may in some cases be more effective to work with private sector or civil society organizations, if they have an influence reducing or removing barriers.

Type 3 refers to the ways in which the implementing agency and the programme manager can 'get round' the problem. Although this is usually the least cost option in the short term, avoiding a barrier is a short cut that should not be taken, as it does not improve the process of commercializing energy efficiency. Programme developers and financiers are likely to choose the cheapest and easiest method of overcoming the barriers - which is usually to avoid them, leaving the task of reducing and removing barriers for other agencies. However, even for private programme developers and financiers, this makes only short-term sense, as they would themselves benefit from barrier removal in the long term.

In the light of this analysis, one can arrive at two approaches to overcome the barriers to private investment. The first one has the primary objective of removing, or at least reducing barriers, which can be referred to as a targeted barrier removal effort. The second approach has the primary objective of maximizing the project's profit. Examples for targeted barrier removal efforts include:

Policy initiatives to remove direct and indirect subsidies for fossil fuels; Initiatives to provide energy efficiency information (e.g., through mass media, Internet) to create awareness;

Initiatives to train programme developers, financiers and government officials, and to provide them with the means and incentives to change the structure of barriers and drivers.

If successfully implemented, these activities are likely to yield high economic and environmental benefits per unit of consumer expenditure on energy.

\section{ANALYSIS OF DRIVERS- SPECIFIC EXAMPLES}

Along with the barriers one should understand the motivation and forces that lead consumers to adopt energy-efficient measures. Information directed towards understanding consumer's 
decision-making behaviour and preferences as well as the behaviour of other stakeholders would give a better understanding of the drivers that push energy efficiency measures. The models and analysis presented above for barriers could be extended for the study of Drivers. Here, we discuss specific examples.

Awareness: It is clear from the above discussion that there are a wide variety of players that can contribute to barrier removal measures, who can also stimulate the drivers and thereby help the penetration of energy efficient technologies. A case in point is the strong competition between technology manufacturers that results in aggressive advertising campaigns. The advertising campaign in this example is the measure (stimulant), and the high level of awareness of energy efficient technologies, thus created, is the driver.

Decrease in technology price levels: A high level of awareness is usually not sufficient to attract private investment and guarantee market success. The general understanding of market mechanisms dictates that price of a technology is an important factor in its speedy penetration. Hence, one can assume that educational/promotional activities are important, even though, there should be other considerations as well. Along with advertisement campaigns, the competition should lead to a decrease in the cost of the technology. Such reductions in prices can safely be assumed to lead to an increase in the sales of the technology.

Increase in energy prices: Cost savings in energy bills through reduced use of energy is one of the reasons for the decision to buy energy efficient equipment. A look at the electricity prices in developing countries over the past few years indicates that nominal electricity prices increased manifold during the 1990s. In real terms, the price increase may be less but is still significant to affect purchasing and investment decisions. Increased energy prices place a higher burden on consumers. If there is a continuous and predictable increase in its price, 
consumers are more likely to be motivated to adopt energy efficient equipment to conserve electricity and heat.

Technology appeal: While analysing drivers, one factor that may be of worth considering is the 'smartness' of the technology. If the energy-efficient equipment gives an impression that it looks 'modern', 'appealing', and 'fashionable', there is a higher probability of consumers purchasing the technology. These non-economic motivations, in general, dominate the decisions primarily of high-income groups, for whom, technological appeal is a major driving factor.

Non-energy benefits: Non-energy benefits are important drivers of energy efficiency. They accrue at the national level, e.g. via improved competitiveness, energy security, job creation, From a consumer perspective, it is often the non-energy benefits that motivate decisions to adopt energy efficient measures. The benefits to the consumer through these measures include (i) improved indoor environment, comfort, health, safety, and productivity; (ii) reduced noise; (iii) labour and time savings; (iv) improved process control; (v) increased reliability, amenity or convenience; and (vi) direct and indirect economic benefits from downsizing or elimination of equipment.

Environmental Regulations: Environmental regulations, if properly designed, can serve as a driver for investments in energy efficiency. In the absence of environmental regulations, the societal costs of electricity generation in the form of air emissions, water use and other environmental impacts are not borne by the energy producer or by the consumer. Consequently, these actors do not see the true societal costs of their production and consumption decisions. Environmental regulations can force producers and consumers to internalize these environmental costs into the price of their energy goods and services in the form of increased environmental compliance costs. These increased environmental costs can send a price signal for increased investments in energy efficiency by making efficiency 
investments comparatively more attractive financially. Not all environmental regulations are created equally, however. If an environmental regulation simply mandates that an industry install a particular pollution control device, then the industry's response will be to seek ways to minimize its cost of compliance with the pollution control requirement and the price signal for efficiency investments will be muted. Once the pollution control device is installed, there will be little incentive to improve the efficiency of the overall production process. If, on the other hand, the environmental regulation uses market mechanisms to reward industry for reducing emissions through, for example, tradable permits, then the industry would have the incentive to improve the efficiency of and continuously improve its manufacturing process and potentially turn the environmental regulations into a source of profitability. A more efficient manufacturing process would naturally follow.

\section{CONCLUSIONS}

This paper attempts to study the barriers and drivers that influence investments in energy efficiency using an actor-oriented approach. It starts with the development of a new taxonomy of barriers/drivers classifying them in terms of profitability and feasibility of private investments in energy efficiency. The barriers are classified into three broad categories, viz., micro, meso and macro. In practice, these barriers are of the following types: perceptual-behavioural, financial-economic, institutional-structural and market oriented. Such classification is expected to help devise the response measures to remove, reduce, or avoid the barriers. The paper is also aimed at understanding which drivers contribute to the successful diffusion of energy efficiency measures. This would facilitate development of appropriate support mechanisms at financial, policy, institutional, regulation, and information levels.

Further, using this taxonomy, the paper develops a theoretical framework which proposes a methodology to analyze the causal relationship between barriers/drivers and the appropriate 
response measures. This work brings out clearly the need for a different set of response measures, depending on which group a barrier belongs to. At the policy level, some barriers can hardly be influenced by an energy efficiency project team, and whoever encounters them has to accept them. But if the 'project' is of a wider scope, let us say, a programme of institutional development financed by international donors, that programme may be able to modify some of the barriers. Hence, it is important to try to assess which barriers are more or less 'unchangeable', and which may be worth tackling by such programmes. This would greatly help both the multilateral and government agencies in devising their strategies in terms of support to future barrier removal programs. This analysis has profound implications for barrier taxonomy, which, in turn, helps design energy efficiency projects. The paper underlines the significance of the identification and classification of real barriers, which is a precondition for the successful diffusion of energy efficient technologies.

Acknowledgement: The author thanks Dr. Hans Nilsson, Stockholm, and Dr T. Srinivas, ECE Department, Indian Institute of Science, Bangalore, India, for critically going through the manuscript and providing excellent suggestions.

\section{References}

1. Edward Vine, Drury Crawley, and Paul Centolella (Eds.). Energy Efficiency and the

Environment: Forging the Link. American Council for an Energy-Efficient Economy, Washington, D.C., 1991.

2. Reddy, B.Sudhakara., Overcoming the energy efficiency gap in India's residential sector, Energy Policy, 2003, 31 (11).

3. Reddy, Amulya K. N., 'Barriers to Improvements in Energy Efficiency'. Energy Policy, 1991, 19 (10): 953-61. 
4. Hollander, J. M., Schneider, T. R.., 1996. Energy-Efficiency: Issues for the Decade. Energy1996, 21 ( 4): 273-87.

5. Sorrell S, Scleich J., Scott S., O'Malley E., Trace F., Boede U., Ostertag K., Radgen P., Reducing barriers to energy efficiency in private and public organisations, Report to the European Commission, in the framework of the Non-Nuclear Energy Programme, 2000, JOULE III. Brighton.

6. Greening LA., Energy efficiency and consumption - the rebound effect - a survey, Energy Policy, 2000, 28: 389-401

7. Saunders, Harry., The Khazzoom-Brookes Postulate and Neoclassical Growth, Energy Journal, 1992, 13 (4), 131-148.

9. Gunn, C., Energy efficiency vs economic efficiency? New Zealand electric sector reform in the context of national energy policy objectives. 1997, Energy policy. 25(2): 241-257.

10. Reddy, B. Sudhakara., 'Barriers to the Diffusion of Renewable Energy Technologies'. Monograph, Centre for Energy and Environment, 2002, UNEP, Denmark.

11. Haugland, T., Bergesen, HO.,Roland, K., 'Energy structures and environmental futures in Europe'. 2000, Oxford University Press, Oxford.

12. Helm, Dieter., 'Energy policy: security of supply, sustainability and competition'. 2002, Energy Policy, 30 (3) : 174-184.

13. Sloman, John., Mark Sutcliffe., 'When markets fail'. In: Vivek Suneja (ed), Understanding Business: Markets. London, UK and New York, NY: Routledge in Association with The Open University, 2000, 147-166.

14.Banerjee, Abhijit., Barry .,D., Solomon. 'Eco-labeling for energy efficiency and sustainability: a meta-evaluation of US programs'. 2003, Energy Policy, 31 (2): 109-123. 15. Stavins Jaffe. The energy efficiency gap, 1994, Energy Policy, 22, 804-810. 
16. Weber, Lukas. 'Some Reflections on Barriers to the Efficient Use of Energy'. 1997, Energy Policy, 25 (10): 833-35.

18. USAID. Opportunities for improving end-use electricity efficiency in India, Electricity Efficiency in India, A Report of the Office of Energy, 1991, Washington D.C.

19. Vine, Edward., Jan Hamrin., Nick Eyre., David Crossely., Michelle Maloney ., Greg Watt. 'Public policy analysis of energy efficiency and load management in changing electricity businesses'. 2003, Energy Policy, 31 (5): 405-430.

20. Sanders, Maria. Green Base Conversion Project (415) 968-8798. Center For Economic Conversion, Mountain View, 1997, CA 94041-1344.

21. William H. Golove., Joseph H, Eto. Market Barriers to Energy Efficiency: A Critical Reappraisal of the Rationale for Public Policies to Promote Energy Efficiency, 1996, Lawrence Berkeley National Laboratory, University of California, Berkeley. Available from http://eande.lbl.gov/EA/EMP/reports/pslx7/38059.pdf

22. GEF (Global Environment Facility). 'Operational Strategy of the Global Environment Facility'. 1996, Washington, DC: Global Environment Facility. 